\title{
Leader 8: Type 2 Diabetes Patients: A Comparison of Baseline Characteristics of Eastern and Western European Participants with Established Cardiovascular Disease in the LEADER Trial
}

\author{
Franek $\mathrm{E}^{1,2 *}$, Rutten $\mathrm{GEHM}^{3}$, Ørsted DD ${ }^{4}$, Baeres $\mathrm{FMM}^{4}$, Mota $\mathrm{M}^{5}$, Jacob $\mathrm{S}^{6}$, Bain $\mathrm{SC}^{7}$, Vidal $\mathrm{J}^{8}$ and Haluzik $\mathbf{M}^{9}$ \\ ${ }^{1}$ Mossakowski Medical Research Centre, Polish Academy of Sciences, Warsaw, Poland \\ ${ }^{2}$ Department of Internal Diseases, Endocrinology and Diabetology, Central Clinical Hospital MSW, Warsaw, Poland \\ ${ }^{3}$ Julius Center for Health Sciences and Primary Care, University Medical Center, Utrecht, The Netherlands \\ ${ }^{4}$ Novo Nordisk, Denmark \\ ${ }^{5}$ University of Medicine and Pharmacy of Craiova, Romania \\ ${ }^{6}$ Kardio Metabolischen Instituts, Villingen--Schwenninge, Germany \\ ${ }^{7}$ Institute of Life Science, Swansea, University Medical School, UK \\ ${ }^{\circledR}$ Universitat de Barcelona, Hospital Clinic Universitari, Barcelona, Spain \\ 9Institute of Endocrinology and Institute of Medical Biochemistry and Laboratory Diagnostics of 1st Faculty of Medicine and General University Hospital, Charles \\ University in Prague, Prague, Czech Republic
}

\begin{abstract}
Aim: The aim of the present analysis was to compare cardiovascular disease risk factors in patients from different countries in Europe, using baseline data from the Liraglutide Effect and Action in Diabetes: Evaluation of cardiovascular outcome Results (LEADER) trial.

Methods: Baseline characteristics and treatments were compared between the subgroup of patients with established cardiovascular disease included in this study from the Eastern European Union (EEU), Western European Union (WEU), and Russia and Serbia (Ru/Se).

Results: Glycaemic control was similar in the EEU and WEU, and poorest in Ru/Se, although WEU patients were older and had longer diabetes duration. Systolic blood pressure was lowest in Ru/Se, whereas diastolic blood pressure was lowest in the WEU. Control of dyslipidaemia was best in the WEU, and worst in Ru/Se. The percentage of patients meeting all three targets for cardiovascular risk factors $\left(\mathrm{HbA}_{1 \mathrm{c}}: \leq 64 \mathrm{mmol} / \mathrm{mol}[8.0 \%]\right.$, blood pressure: $<140 /<90 \mathrm{mmHg}$ and low-density lipoprotein [LDL]-cholesterol: $1.8 \mathrm{mmol} / \mathrm{L}$ [70 mg/dL]) was $9.7 \%, 6.4 \%$ and $3.2 \%$ in the WEU, EEU and Ru/Se, respectively. Metformin and sulphonylurea treatment was more frequent in the EEU than WEU and Ru/Se. Insulin, in turn, was used less frequently in the EEU than WEU and Ru/Se. The use of newer drugs was small and differences could not be subjected to statistical analyses. Statins were used most frequently in WEU countries and least frequently in Ru/Se.
\end{abstract}

Conclusion: The high cardiovascular risk patients in the WEU were older and had longer diabetes duration, when compared with EEU and Ru/Se. Despite this, they had a lower body mass index (BMI), similar blood pressure and better lipid control. Although the differences were small, the percentage of patients meeting all three treatment targets was low across all regions studied.

Keywords: Diabetes control; Blood pressure; Lipids; European Union; Russia; Serbia

\section{Introduction}

Diabetes is a global burden. It is predicted that, in 2040, the prevalence will reach 642 million patients worldwide [1]. There are, however, many regional and national differences in the incidence and prevalence of diabetes and associated complications. These differences may be partially explained by varying prevalence of obesity, differences in age distribution and different health service expenditures. The 45 years of separation between Western and Eastern Europe, the "iron curtain", has resulted not only in the above-mentioned differences (mainly economically driven), but also in distinct differences in the cardiovascular disease (CVD) epidemiology, which, in turn, has led to differences in life expectancy between these regions [2].

The Czech Republic and Poland joined the European Union (EU) in 2004, followed by Romania in 2007. However, major political, social and economic changes in these countries began in 1989, increasing the living standards of these populations. For example, these changes led the gross domestic product in Poland to increase by $382 \%$ between
1995 and 2013 [3] and similar changes in the health expenditure in some Eastern EU countries [4].

The gross domestic product of the Eastern EU is still much lower than that of the 'core' EU (countries including Germany, France and The Netherlands), but is already close to that of Southern EU countries like Greece, Portugal and even Spain [5]. The health service in Eastern

${ }^{*}$ Corresponding author: Prof. Edward Franek, Department of Internal Diseases Endocrinology and Diabetology Central Clinical Hospital MSW, ul. Woloska 137, 02-507 Warsaw, Poland, Tel: +48225081405; E-mail: Edward.Franek@cskmswia.pl

Received January 11, 2016; Accepted February 10, 2016; Published February 15,2016

Citation: Franek E, Rutten GEHM, Ørsted DD, Baeres FMM, Mota M, et al. (2016) Leader 8: Type 2 Diabetes Patients: A Comparison of Baseline Characteristics of Eastern and Western European Participants with Established Cardiovascular Disease in the LEADER Trial. J Diabetes Metab 7: 646. doi:10.4172/21556156.1000646

Copyright: $\odot 2016$ Franek E, et al. This is an open-access article distributed under the terms of the Creative Commons Attribution License, which permits unrestricted use, distribution, and reproduction in any medium, provided the original author and source are credited. 
Citation: Franek E, Rutten GEHM, Ørsted DD, Baeres FMM, Mota M, et al. (2016) Leader 8: Type 2 Diabetes Patients: A Comparison of Baseline Characteristics of Eastern and Western European Participants with Established Cardiovascular Disease in the LEADER Trial. J Diabetes Metab 7: 646. doi:10.4172/2155-6156.1000646

Page 2 of 6

EU is improving and it seems to be similar to that of Western EU in many areas, although this topic is still an area of debate (e.g. mortality after surgery $[6,7])$. There is also indirect proof for an improvement in healthcare delivery in the former communist countries with increasing longevity of people living in these areas [8].

The Liraglutide Effect and Action in Diabetes: Evaluation of cardiovascular outcome Results (LEADER) trial [9] is a cardiovascular safety study that in Europe recruited patients with type 2 diabetes mellitus (T2DM) and either prior CVD or a high risk of CVD from 16 EU countries (Austria, Belgium, Czech Republic, Denmark, Finland, France, Germany, Greece, Ireland, Italy, The Netherlands, Poland, Romania, Spain, Sweden and the United Kingdom), and two countries outside the EU (Republic of Russia and Serbia/Montenegro). Recruitment started in 2010 and finished in 2012. With the same inclusion and exclusion criteria across Europe, the LEADER trial offers a unique opportunity to compare patients randomized across Eastern and Western Europe.

The aim of this analysis was to compare the baseline demographic, anthropometric and biochemical parameters, as well as treatment, of patients with T2DM included in the LEADER study across Europe.

\section{Patients and Methods}

The LEADER study is an international, randomized, doubleblind, placebo-controlled trial with the primary endpoint of assessing the cardiovascular safety of liraglutide in patients with T2DM. The study design and aims have been described previously [9]. In brief, the LEADER study enrolled two groups of patients, both with a glycated hemoglobin $\left(\mathrm{HbA}_{1 \mathrm{c}}\right)$ level $\geq 53 \mathrm{mmol} / \mathrm{mol}$ ( $\left.\geq 7.0 \%\right)$. One group included patients with $\mathrm{T} 2 \mathrm{DM} \geq 50$ years of age with prior CVD, cerebrovascular disease, peripheral vascular disease, chronic renal failure or chronic heart failure [9]. The other group consisted of patients without prior CVD, $\geq 60$ years of age with one or more of the following cardiovascular risk factors: microalbuminuria or proteinuria; hypertension and left ventricular hypertrophy by electrocardiogram or imaging; left ventricular dysfunction by imaging; or ankle-brachial index $<0.9$ [9]. The most important exclusion criteria were: type 1 diabetes mellitus; use of a glucagon-like peptide 1 receptor agonist, dipeptidyl peptidase- 4 inhibitor, or insulins other than human neutral protamine Hagedorn insulin; use of long-acting analogues or premixed insulins within 3 months before screening; acute decompensation of glycemic control; and acute coronary or cerebrovascular event 14 days before randomisation. The required sample size was calculated and is shown in the baseline paper [9]. The trial was powered to demonstrate non-inferiority of liraglutide versus placebo in terms of first major cardiovascular event, and was designed and conducted according to the Declaration of Helsinki and approved by local ethical committees [10]. All patients signed a consent form before any study procedure was performed.

As there were only a small number of patients in the European cohort who had no prior CVD $(n=411)$, further division of this population would have resulted in a sample size too small for meaningful analysis; therefore, this analysis was limited to participants with prior CVD ( $\mathrm{n}=2845)$. Race and ethnicity were documented at the beginning of the study. Full medical history, anthropometric measures and $\mathrm{HbA}_{1 \mathrm{c}}$, serum creatinine, high-density lipoprotein (HDL)-and lowdensity lipoprotein (LDL)-cholesterol and triglyceride concentrations were obtained, as well as urine samples for albumin/creatinine ratios. All samples were obtained after 12 hours of fasting and sent to a central laboratory for analysis. Estimated glomerular filtration rate (eGFR) was calculated based on the Modification of Diet in Renal Disease equation [11].

For the purpose of this analysis, European countries were divided into different strata: the Eastern EU was defined as the Czech Republic, Poland and Romania. The Republic of Russia and Serbia/Montenegro were combined due to insufficient numbers of participants (Russia/ Serbia) and analysed as a separate category. The Western EU comprised Austria, Belgium, Denmark, Finland, France, Germany, Greece, Ireland, Italy, The Netherlands, Spain, Sweden and the United Kingdom. Western EU was additionally divided into the 'core EU' (Austria, Belgium, France, Germany, Ireland, The Netherlands and the United Kingdom), Scandinavia (Denmark, Finland and Sweden) and the Southern EU (Greece, Italy and Spain). By further subdividing the Western EU data, regions with similar healthcare systems could be compared. The sub-regional data are provided as supplementary material only (see Supplementary Material).

For this study, targets for metabolic control were defined and the proportion of participants achieving target at baseline was recorded. The on-target values for $\mathrm{HbA}_{1 \mathrm{c}}$ were $\leq 64 \mathrm{mmol} / \mathrm{mol}$ $(8.0 \%)$ and $\leq 53 \mathrm{mmol} / \mathrm{mol}(7.0 \%)$. These values were based on American Diabetes Association/European Association for the Study of Diabetes as well as local guidelines $[12,13]$. The target for LDLcholesterol was $<1.8 \mathrm{mmol} / \mathrm{L}(70 \mathrm{mg} / \mathrm{dL})$.

Targets for hypertension treatment were defined as follows: a systolic blood pressure (SBP) $<140 \mathrm{mmHg}$ and a diastolic blood pressure (DBP) $<90 \mathrm{mmHg}$ [14], or a more stringent DBP target of $<80 \mathrm{mmHg}$ [14]. Resistant hypertension was defined as the prescription of four or more antihypertensive agents at baseline (or the prescription of three or more agents for those with blood pressure $\geq 140 / 90 \mathrm{mmHg}$ ) [15]. A combined composite target was defined as the percentage of patients achieving all three target values for the key cardiovascular risk factors $\left(\mathrm{HbA}_{1}: \leq 64 \mathrm{mmol} / \mathrm{mol}[8.0 \%]\right.$, blood pressure: $<140 / 90 \mathrm{mmHg}$ and LDL-cholesterol: $<1.8 \mathrm{mmol} / \mathrm{L}$ $[70 \mathrm{mg} / \mathrm{dL}])$. An additional, more stringent, composite target was also examined, defined as $\mathrm{HbA}_{1 \mathrm{c}} \leq 53 \mathrm{mmol} / \mathrm{mol}$ ( $\leq 7.0 \%$ ), blood pressure $<140 / 80 \mathrm{mmHg}$; LDL-cholesterol $<1.8 \mathrm{mmol} / \mathrm{L}(70 \mathrm{mg} /$ $\mathrm{dL})$.

Use of medication at baseline was coded using Anatomical Therapeutic Chemical (ATC) Classification System codes [16]. Antihypertensive medication codes were C02, C07, $\mathrm{C} 08$ and C09. Oral antidiabetic drugs (OADs) were coded as: metformin, A10BA; sulphonylurea, A10BB; glucosidase inhibitors, A10BF; thiazolidinediones, A10BG; other OADs, A10BX; combination OAD, A10BD; and insulin, A10A. Information on statin use was defined by ATC code C10A, and acetylsalicylic acid by drug names 'acetylsalicylate lysine' or 'acetylsalicylic acid'.

\section{Statistical Analysis}

Distributions are described by mean (standard deviation) and median frequencies and percentages (\%) for categorical variables. The variation across EU sub-regions of continuous variables was assessed using one-way analysis of variance, whereas for categorical variables or factors, the chi-square or Fisher's exact test was used. A two-sided $p$-value $<0.01$ was considered statistically significant. All analyses were performed using SAS version 9.3 (SAS Institute, Cary, NC, USA). Analyses were performed using data available at the time, prior to the end of the study. 
Citation: Franek E, Rutten GEHM, Ørsted DD, Baeres FMM, Mota M, et al. (2016) Leader 8: Type 2 Diabetes Patients: A Comparison of Baseline Characteristics of Eastern and Western European Participants with Established Cardiovascular Disease in the LEADER Trial. J Diabetes Metab 7: 646. doi:10.4172/2155-6156.1000646

\section{Results}

Comparisons of patients from the Eastern and Western EU and Russia/Serbia are shown in (Tables 1 and 2). These comparisons highlighted the differences in age and diabetes duration between the European regions (Table 1). Participants from the Western EU were older, with a mean age of 65.9 years, compared with the Eastern EU and Russia/Serbia (62.1 and 60.8 years, respectively) (Table 1). Western EU participants also had a longer history of diabetes and lower body mass index (BMI) than the other regions (diabetes duration: $12.4 \pm 7.7$ compared with $9.5 \pm 6.7$ and $9.0 \pm 6.0$ years for the Eastern EU and Russia/Serbia, respectively; BMI: $32.6 \pm 5.7$ vs. $33.7 \pm 5.9$ and $34.1 \pm$ $\left.5.8 \mathrm{~kg} / \mathrm{m}^{2}\right)$. Mean $\mathrm{HbA}_{1 \mathrm{c}}$ did not significantly differ between the regions (67-69 $\mathrm{mmol} / \mathrm{mol}[8.3-8.5 \%])$.

A similar proportion of participants across the regions met the blood pressure target of $<140 / 90 \mathrm{mmHg}$ (Figure 1). Mean SBP levels were similar between the Eastern and Western EU and slightly lower in Russia/Serbia. DBP levels were lowest in Western EU participants $(77.4 \pm 10.5$ compared to $81.3 \pm 9.5$ and $82.3 \pm 8.1$ $\mathrm{mmHg}$ for Eastern EU and Russia/Serbia, respectively) ( $<<0.0001$ vs. Eastern EU). Control of dyslipidaemia was most rigorous in the Western EU (mean levels at baseline: LDL: $2.2 \pm 0.8 \mathrm{mmol} / \mathrm{L}$; HDL: $1.16 \pm 0.32 \mathrm{mmol} / \mathrm{L}$; triglycerides: $2.1 \pm 1.5 \mathrm{mmol} / \mathrm{L})$ and poorest in Russia/Serbia (LDL: $3.0 \pm 1.0 \mathrm{mmol} / \mathrm{L}$; HDL: $1.18 \pm 0.31 \mathrm{mmol} / \mathrm{L}$; triglycerides: $2.5 \pm 1.9 \mathrm{mmol} / \mathrm{L})$.

The percentage of patients achieving the composite treatment target $\left(\mathrm{HbA}_{1 \mathrm{c}}\right.$, blood pressure and LDL-cholesterol) did not exceed $10 \%$ in any region (Table 1; Figure 1). The percentage of patients achieving LDLcholesterol targets in the Western EU was 3.6-fold greater than in Russia/ Serbia (Figure 1). When the more stringent targets $\left(\mathrm{HbA}_{1 \mathrm{c}}<53 \mathrm{mmol} / \mathrm{mol}\right.$
[ $<7.0 \%]$ and blood pressure $<140 / 80 \mathrm{mmHg}$ ) were applied, the percentage of patients on target was lower than $2 \%$ across the whole of Europe, except in Scandinavia (2.4\%, see Supplementary Table 1).

Although the number of current smokers was similar across Europe, the number of patients who had never smoked was highest (60.1\%), and previous smokers lowest (28.2\%), in Russia/Serbia (Table 1). There were also some differences in the proportion of previous smokers and those who have never smoked in the Scandinavian, southern and 'core' EU countries (see Supplementary Table 1).

With regard to medications at baseline, the proportion of participants treated with metformin was similar across Europe $(82.3 \%$ vs. $78.2 \%$ and $79 \%$, for Western EU, Eastern EU and Russia/Serbia, respectively). Use of oral OADs differed considerably between the regions. This was even more distinct in the case of sulphonylureas, which were administered least frequently in the Western EU $(36.3 \%$ compared with $63.5 \%$ and $72.3 \%$ of patients from the Eastern EU and Russia/Serbia, respectively). The differences in newer drug classes were not assessed in terms of significance of difference because of the small numbers of patients on these drugs. Insulin was used less often in the Eastern EU than in the Western EU and Russia/Serbia (Table 2). Statins, in turn, were used least frequently in Russia/Serbia and most frequently in the Western EU (48.7\% and $83.8 \%$ of patients, respectively; see Table 2).

\section{Discussion}

The main finding of this study is that there are small but noteworthy regional differences on important parameters between participants from the Eastern and Western EU and from Russia/Serbia in the LEADER trial.

\begin{tabular}{|c|c|c|c|c|c|}
\hline Parameter & Western EU (1905) & Eastern EU (564) & $\begin{array}{l}\text { Russia and Serbia } \\
\text { (Ru/Se) }(n=376)\end{array}$ & $\begin{array}{c}\text { p-value, Eastern EU } \\
\text { vs. Ru/Se }\end{array}$ & $\begin{array}{l}\text { p-value, Eastern EU } \\
\text { vs. Western EU }\end{array}$ \\
\hline Age [y] & $65.9 \pm 7.5$ & $62.1 \pm 6.9$ & $60.8 \pm 6.4$ & $<0.01$ & $<0.0001$ \\
\hline Gender, male [n (\%)] & $1400(73.5)$ & $344(61)$ & $162(43.1)$ & $<0.0001$ & $<0.0001$ \\
\hline BMI $\left[\mathrm{kg} / \mathrm{m}^{2}\right]$ & $32.6 \pm 5.7$ & $33.7 \pm 5.9$ & $34.1 \pm 5.8$ & NS & $<0.0001$ \\
\hline Diabetes duration [y] & $12.4 \pm 7.7$ & $9.5 \pm 6.7$ & $9.0 \pm 6.0$ & NS & $<0.0001$ \\
\hline $\mathrm{HbA}_{1 \mathrm{c}}[\mathrm{mmol} / \mathrm{mol}(\%)]$ & $67 \pm 14(8.3 \pm 1.3)$ & $67 \pm 14(8.3 \pm 1.3)$ & $69 \pm 14(8.5 \pm 1.3)$ & NS & NS \\
\hline Systolic BP [mmHg] & $140.8 \pm 19.0$ & $140.1 \pm 15.8$ & $137.3 \pm 14.0$ & $<0.01$ & NS \\
\hline Diastolic BP [mmHg] & $77.4 \pm 10.5$ & $81.3 \pm 9.5$ & $82.3 \pm 8.1$ & NS & $<0.0001$ \\
\hline eGFR (MDRD) [ml/min/m²] & $77.7 \pm 27.1$ & $88.2 \pm 24.5$ & $89.3 \pm 20.2$ & NS & $<0.0001$ \\
\hline Albumin/creatinine ratio $[\mathrm{mg} / \mathrm{mmol}]$ & $18.2 \pm 62.0$ & $8.8 \pm 29.7$ & $6.2 \pm 16.0$ & NS & $<0.01$ \\
\hline LDL-cholesterol [mmol/l] & $2.2 \pm 0.8$ & $2.5 \pm 0.9$ & $3.0 \pm 1.0$ & $<0.0001$ & $<0.0001$ \\
\hline HDL-cholesterol [mmol/l] & $1.16 \pm 0.32$ & $1.19 \pm 0.31$ & $1.18 \pm 0.31$ & NS & NS \\
\hline Triglycerides [mmol/l] & $2.1 \pm 1.7$ & $2.3 \pm 2.1$ & $2.5 \pm 1.9$ & NS & NS \\
\hline Current smokers [n (\%)] & $252(13.2)$ & $67(11.9)$ & $44(11.7)$ & NS & NS \\
\hline Previous smokers [n (\%)] & $1087(57.1)$ & $244(43.3)$ & $106(28.2)$ & $<0.0001$ & $<0.0001$ \\
\hline Never smoked [n (\%)] & $566(29.7)$ & $253(44.9)$ & $226(60.1)$ & $<0.0001$ & $<0.0001$ \\
\hline BP above $140 / 80 \mathrm{mmHg}[\mathrm{n}(\%)]$ & $1243(65.2)$ & $406(72)$ & $283(75.3)$ & NS & $<0.01$ \\
\hline BP above $140 / 90 \mathrm{mmHg}$ [n (\%)] & $1004(52.8)$ & $309(54.8)$ & $187(49.7)$ & NS & NS \\
\hline LDL-cholesterol above target [n (\%)] & $1121(58.8)$ & $412(73)$ & $306(81.4)$ & $<0.0001$ & $<0.0001$ \\
\hline $\mathrm{HbA}_{1 \mathrm{c}}>64 \mathrm{mmol} / \mathrm{mol}(8 \%)[\mathrm{n}(\%)]$ & $883(46.4)$ & $282(50.0)$ & $222(59.0)$ & $<0.01$ & NS \\
\hline $\mathrm{HbA}_{1 \mathrm{c}}>53 \mathrm{mmol} / \mathrm{mol}(7 \%)[\mathrm{n}(\%)]$ & $1735(91.1)$ & $510(90.4)$ & $344(91.5)$ & NS & NS \\
\hline On all 3 targets (less stringent) [n (\%)] & $185(9.7)$ & $36(6.4)$ & $12(3.2)$ & NS & NS \\
\hline On all 3 targets (more stringent) [n (\%)] & $29(1.5)$ & $4(0.7)$ & $1(0.3)$ & NS & NS \\
\hline
\end{tabular}

BMI: Body mass index; BP: Blood pressure; eGFR: Estimated glomerular filtration rate; EU: European Union; HDL: High-density lipoprotein; LDL: Low-density lipoprotein; MDRD: Modification of Diet in Renal Disease; NS: Not significant; Ru/Se: Russia/Serbia; SD: Standard deviation.

Table 1: Comparison of basal demographic, anthropometric and biochemical parameters between patients with prior cardiovascular disease in the Western and Eastern $\mathrm{EU}$, and in Russia/Serbia. Data shown as mean \pm SD or $\mathrm{n}(\%)$. 
Citation: Franek E, Rutten GEHM, Ørsted DD, Baeres FMM, Mota M, et al. (2016) Leader 8: Type 2 Diabetes Patients: A Comparison of Baseline Characteristics of Eastern and Western European Participants with Established Cardiovascular Disease in the LEADER Trial. J Diabetes Metab 7: 646. doi:10.4172/2155-6156.1000646

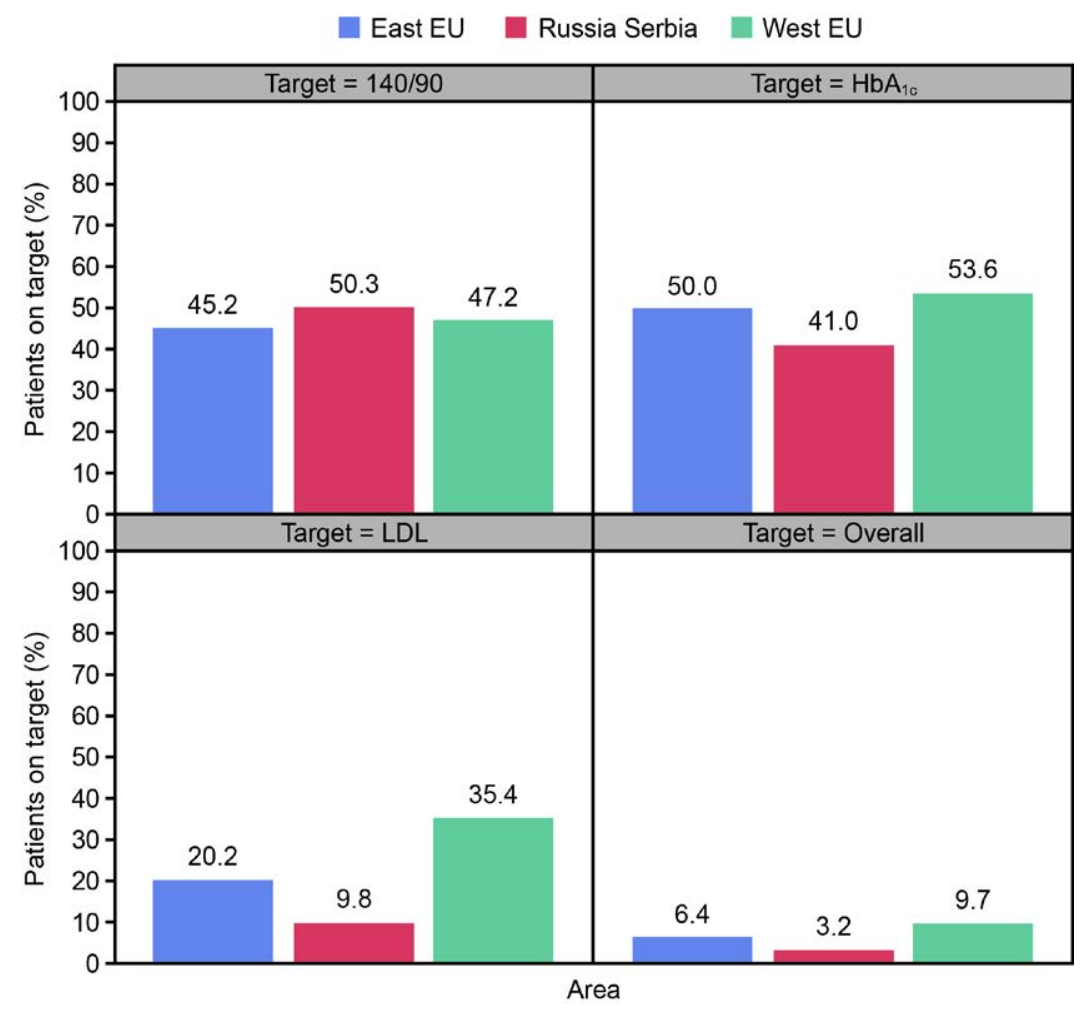

Figure 1: Percentage of patients meeting treatment targets: $\mathrm{BP}<140 / 90 \mathrm{mmHg}$, LDL-cholesterol $<1.8 \mathrm{mmol} / \mathrm{l}$ and $\mathrm{HbA}$.c $\leq 64 \mathrm{mmol} / \mathrm{mol}(\leq 8.0 \%)$ and all three targets together. BP, blood pressure; EU, European Union; $\mathrm{HbA}_{1 \mathrm{c}}$, glycated haemoglobin; LDL, low-density lipoprotein

\begin{tabular}{|c|c|c|c|c|c|}
\hline Parameter & $\begin{array}{c}\text { Eastern EU } \\
\quad(564)\end{array}$ & $\begin{array}{l}\text { Russia and Serbia } \\
\text { (Ru/Se) (n=376) }\end{array}$ & Western EU (1905) & $\begin{array}{c}p \text {-value, Eastern EU vs. } \\
\text { Ru/Se }\end{array}$ & $\begin{array}{c}p \text {-value, Eastern EU vs. } \\
\text { Western EU }\end{array}$ \\
\hline Metformin & $464(82.3)$ & $297(79)$ & $1489(78.2)$ & NS & NS \\
\hline Sulphonylureas & $358(63.5)$ & $272(72.3)$ & $692(36.3)$ & $<0.01$ & $<0.0001$ \\
\hline Thiazolidinedione & $12(2.1)$ & $2(0.5)$ & $86(4.5)$ & NS & NS \\
\hline Alpha-glucosidase inhibitors & $53(9.4)$ & $1(0.3)$ & $18(0.9)$ & $<0.0001$ & $<0.0001$ \\
\hline Other OADs* & $0(0)$ & $2(0.5)$ & $144(7.6)$ & NS & $<0.0001$ \\
\hline Fixed combinations of OADs* & $4(0.7)$ & $22(5.9)$ & $16(0.8)$ & $<0.0001$ & NS \\
\hline Insulin treatment [n (\%)] & $131(23.2)$ & $133(35.4)$ & $845(44.4)$ & $<0.0001$ & $<0.0001$ \\
\hline $\begin{array}{c}\text { No. of antihypertensive } \\
\text { medications: } \\
0 \\
1 \\
2 \\
3 \\
4\end{array}$ & $\begin{array}{c}35(6.2) \\
118(20.9) \\
252(44.7) \\
125(12.2) \\
34(6.0)\end{array}$ & $\begin{array}{c}5(1.3) \\
98(26.1) \\
204(54.3) \\
56(14.9) \\
13(3.5)\end{array}$ & $\begin{array}{c}132(6.9) \\
496(26.0) \\
839(44.0) \\
340(17.8) \\
98(5.1)\end{array}$ & $<0.0001$ & NS \\
\hline Resistant hypertension [n (\%)] & $111(19.7)$ & $47(12.5)$ & $294(15.4)$ & $<0.01$ & NS \\
\hline Statin use [n (\%)] & $425(75.4)$ & $183(48.7)$ & $1597(83.8)$ & $<0.0001$ & $<0.0001$ \\
\hline Acetylsalicylic acid use [n (\%)] & $375(66.5)$ & $182(48.4)$ & $1285(67.5)$ & $<0.0001$ & NS \\
\hline
\end{tabular}

*The use of dipeptidyl peptidase-4 inhibitors was not permitted in the LEADER study.

EU: European Union; NS: Not significant; OAD: Oral antidiabetic drug; Ru/Se: Russia/Serbia. Resistant hypertension defined as the use at baseline of at least four different antihypertensives (or the prescription of three or more agents for those with blood pressure $\geq 140 / 90 \mathrm{mmHg}$ ).

Table 2: Comparison of antidiabetic, antihypertensive and statin treatments in patients with prior cardiovascular disease from Western and Eastern EU, and from Russia/ Serbia. Data shown as n (\%).

\section{Dyslipidaemia control and treatment}

The percentage of patients achieving LDL-cholesterol targets was lowest in Russia/Serbia, and highest in the Western EU (Figure 1). This cannot be explained by different treatment targets set by guidelines in Russia/Serbia, as these countries have not issued specific guidelines; and for the most likely used guidelines, the target LDL-cholesterol for prior CVD patients was $<1.8 \mathrm{mmol} / \mathrm{L}$ ( $70 \mathrm{mg} / \mathrm{dL}$ ) in the LEADER recruitment period [12] and later on [17]. A possible explanation is that it is due to the less frequent use of statins in Russia/Serbia in comparison with the EU countries. Therefore, the percentage of patients below target could reflect the number of those who are treated. Again, this may not be a result of guideline recommendations, but could instead be due to socio-economic circumstances. The latter is supported by the 
fact that the Western EU, as the richest region, was also the region with the highest percentage of patients taking statins.

Despite the fact that, in the EU, reimbursement is most often provided by government or national healthcare plans, about $20 \%$ of patients with a history of CVD are not treated with a statin, and even in the Western EU, only about $40 \%$ of patients are at LDL target $(1.8 \mathrm{mmol} / \mathrm{L}$; approximately $50 \%$ of those treated with statins). Taking into account the high cardiovascular risk of that population and the role of LDL-cholesterol as a cardiovascular risk factor, this is an important clinical challenge. However, comparable results are achieved in similar populations across Europe [18]. The percentage of patients on target is much higher than it was 20 years ago [18], but similar (at least in the Eastern EU) to the values observed in 2004 [19], which suggests that in the Eastern EU, most of the improvements occurred before joining the EU.

\section{Hypertension control and treatment}

Blood pressure levels were similar in different regions across Europe, although SBP was lowest in Russia/Serbia and DBP lowest in the Western EU. The number of patients with resistant hypertension was lowest in Russia/Serbia (and in Southern EU), whereas it was highest in Eastern EU. Interestingly, the percentage of patients at blood pressure target was also lowest in Russia/Serbia (highest in Western $\mathrm{EU})$

Taken together, blood pressure targets were not reached by a high proportion of participants in the remaining regions of the EU. This is in accordance with previous results, such as those reported from the BP-CARE (blood pressure control rate and cardiovascular risk profile) study, which found that blood pressure levels in Eastern and Central European countries (Albania, Bosnia, Czech Republic, Latvia, Romania, Serbia, Slovakia and Ukraine) averaged 150/90 $\mathrm{mmHg}$, with only $27.1 \%$ achieving blood pressure control of $<140 / 90 \mathrm{mmHg}$ [20]. Additionally, prior to the introduction of more stringent blood pressure control targets, the World Health Organization's MONICA project (monitoring trends and determinants in cardiovascular disease), which compared blood pressure levels in Western, Northern, Southern and Eastern (Poland, Lithuania and Serbia) Europe, yielded levels ranging from $130-140 \mathrm{mmHg}$ in all regions [21,22].

Interestingly, there were no large numerical differences in the use of antihypertensive medications between the regions.

\section{T2DM control and management}

The percentage of patients treated with metformin at baseline was similar across the regions (Table 2), and in the Eastern EU it is about $30 \%$ higher than reported in 2004 [19]. However, sulphonylureas are used much more frequently in the Eastern EU. That may be partially explained by more frequent use of other OADs in the Western EU (7.6\% of participants vs. $0 \%$ and $0.5 \%$ for Eastern EU and Russia/Serbia, respectively), with the exception of the alpha-glucosidase inhibitor, which is more frequently used in the Eastern EU (although not in Russia/Serbia). However, the differences in OAD treatment could be explained by an earlier start of insulin treatment in the Western EU than in the Eastern EU, as the percentage of patients treated with insulin was highest in the Western EU. In this regard, consideration should also be given to the exclusion criteria of this trial, which would have excluded patients using dipeptidyl peptidase- 4 inhibitors within 3 months prior to screening [9]. Data from the SAVOR-TIMI 53 also showed a greater percentage of patients treated with insulin in the Western EU than in the Eastern EU, although the difference in that trial was only 5\% [23]. Another possible explanation is the longer duration of diabetes in the
Western EU (Table 1), potentially resulting from earlier diagnosis due to better access to healthcare; this would have increased the percentage of insulin-treated patients, even if insulin had been started at the same time. Other reasons, like pricing of insulin, may also play a role. In spite of those differences, the percentage of patients below target $\mathrm{HbA}_{1 c}$ ( $\leq 64 \mathrm{mmol} / \mathrm{mol}[8.0 \%]$ ) was similar between Eastern and Western EU (50.0\% vs. $53.6 \%$, respectively); a lower proportion of patients in Russia/Serbia was below target (41.0\%). Overall, it seems that, in spite of differences in diabetes treatment and the costs of those treatments [24] between European regions, metabolic control is similar across Europe and remains relatively unsatisfactory, especially if the target is considered to be an $\mathrm{HbA}_{1 \mathrm{c}}$ value of $\leq 53 \mathrm{mmol} / \mathrm{mol}$ (7.0\%) (Table 1).

\section{Combined target for $\mathrm{HbA}_{1 \mathrm{c}}$, blood pressure, and LDL}

As shown in Table 1 and Supplementary Table 1, only a small population of LEADER patients across Europe achieved all three goals of treatment, regardless of whether less or more stringent targets were taken into account (see 'Patients and methods' for details). The differences between the regions may be significant, but they are not of great importance when we consider that the percentage of patients achieving all three targets does not exceed $10 \%$ in any country or region of Europe in what is a specifically high cardiovascular risk population Figure 1).

\section{Albuminuria and kidney function}

Albuminuria, measured as albumin/creatinine ratio, was lowest in Russia/Serbia but also low in the Eastern EU countries. In contrast, in the Western EU it was twice as high, although the mean value did not exceed $20 \mathrm{mg} / \mathrm{mmol}$. Kidney function (measured as eGFR) was also lowest in the Western EU, although this does not necessarily mean that the prevalence of diabetic kidney disease is higher in the Western EU, but rather it may reflect the older age of patients and longer duration of diabetes treatment in that region.

\section{Smoking}

While the number of current smokers included in the study was similar across all European regions, there were significantly more patients who had never smoked and fewer former smokers in Russia/ Serbia compared to the Western and Eastern EU.

These results are in contrast to previously published data. Zatoński et al. performed a 'Closing the Gap' project [25], which compared the numbers of current, former and 'never' smokers in different European countries, showing the highest percentage of smoking men in Russia (aged 20-64 years $=66.2 \%$, although only $20.4 \%$ of women). This difference in proportions between the two studies could be explained by the likelihood that, in patients with established CVD, the number of individuals who have already stopped smoking is higher.

Furthermore, McKee et al. observed that 20 years ago, smoking rates in Russian men were very high compared to those in women [26]. The Russian/Serbian population enrolled in the LEADER trial includes a higher proportion of women $(56.9 \%)$, which may further explain the high numbers of non-smokers and former smokers seen. Another possibility is a higher death rate for patients with established CVD in these countries [27], leading to inclusion of those who have survived.

\section{Limitations}

The study sample is not representative of the general T2DM population. Instead, it includes patients with established CVD, recruited from diabetology and cardiology (mostly outpatients) units to 
Citation: Franek E, Rutten GEHM, Ørsted DD, Baeres FMM, Mota M, et al. (2016) Leader 8: Type 2 Diabetes Patients: A Comparison of Baseline Characteristics of Eastern and Western European Participants with Established Cardiovascular Disease in the LEADER Trial. J Diabetes Metab 7: 646. doi:10.4172/2155-6156.1000646

Page 6 of 6

partake in an international randomized controlled trial. Consequently, these patients do not necessarily represent the underlying population, making it difficult to ascertain differences between geographic regions with respect to participants' characteristics and health. Additionally, the stringent inclusion/exclusion criteria used in the LEADER study limit the extrapolation of findings to other populations. We can only speculate about the reasons for the differences between EU regions, as the LEADER study was not designed for this analysis. Factors that were not assessed, but could have impacted the described observations include differences in the genetic predispositions of participants to CVD, and the implementation of exercise and diet programmes. Similarly, differences in the care patterns and healthcare systems and costs, as well as availability and obtainability of treatments in each participating country are of importance. Moreover, the 'no prior CVD' group would have been a useful population to analyze; unfortunately, the sample size $(n=411)$ made this investigation unfeasible. Further investigations using cross-sectional surveys, patient registries, medical records or population-based longitudinal studies would prove useful in confirming differences between geographical regions.

\section{Conclusions}

LEADER patients with established CVD in the Western EU were, on average, older and with longer duration of diabetes, but had lower BMI and were better controlled in terms of hypertension and LDLcholesterol levels compared with participants from the Eastern EU and Russia/Serbia. While the observed differences were generally small, it is important to note that the percentage of patients at a combined target for $\mathrm{HbA}_{1 \mathrm{c}}$, blood pressure and LDL-cholesterol at baseline did not exceed $10 \%$ in any region of Europe.

\section{Acknowledgment}

The authors are grateful to Watermeadow Medical, UK, for editorial assistance in the development of this manuscript. This assistance was funded by Novo Nordisk. Henrik Wachmann, Department of Biostatistics, Novo Nordisk A/S, assisted with the statistical analysis.

\section{Author contribution statement}

E Franek, D Orsted and F Baeres performed data collection. E Franek, D Orsted, F Baeres and M Haluzik conducted data analysis. All authors were involved in the study design, data interpretation and writing of the manuscript. All authors approved the final version of the manuscript and take full responsibility for the content.

\section{Funder's Involvement}

Novo Nordisk is the sponsor of the LEADER trial. The sponsor had a role in the review of this manuscript for scientific accuracy.

\section{References}

1. International Diabetes Federation (2015) IDF Diabetes Atlas. ( $7^{\text {th }}$ edn), International Diabetes Federation, Brussels, Belgium.

2. Velkova A, Wolleswinkel-van den Bosch JH, Mackenbach JP (1997) The EastWest life expectancy gap: differences in mortality from conditions amenable to medical intervention. Int J Epidemiol 26: 75-84.

3. Central Statistical Office (2014) Statistical Yearbook of the Republic of Poland. Central Statistical Office, Warsaw, Poland

4. WHO Regional Office for Europe (2015) European Health for all Database (HFA-DB). World Health Organization, Copenhagen, Denmark.

5. Economy of Europe (2015) http://en.wikipedia.org/wiki/Economy_of_Europe

6. Pearse RM, Moreno RP, Bauer P, Pelosi P, Metnitz P, et al. (2012) Mortality after surgery in Europe: a 7 day cohort study. Lancet 380: 1059-1065.

7. Franek E, Osinska B, Czech M, Figat J (2013) Mortality after surgery in Europe. Lancet 381: 369-370.

8. Gavrilova NS, Gavrilov LA (2009) Rapidly aging populations: Russia and
Eastern Europe. In: International Handbook of Population Aging. Springer Science+Business Media B.V., Dordrecht, Netherlands

9. Marso SP, Poulter NR, Nissen SE, Nauck MA, Zinman B, et al. (2013) Design of the liraglutide effect and action in diabetes: evaluation of cardiovascular outcome results (LEADER) trial. Am Heart J 166: 823-830.

10. World Medical Association (2013) World Medical Association Declaration of Helsinki: ethical principles for medical research involving human subjects. JAMA 310: 2191-2194.

11. Levey AS, Bosch JP, Lewis JB, Greene T, Rogers N, et al. (1999) A more accurate method to estimate glomerular filtration rate from serum creatinine: a new prediction equation. Modification of Diet in Renal Disease Study Group. Ann Intern Med 130: 461-470.

12. Inzucchi SE, Bergenstal RM, Buse JB, Diamant M, Ferrannini E, et al. (2012) Management of hyperglycemia in type 2 diabetes: A patient centered approach. Position statement of the American Diabetes Association (ADA) and European Association for the Study of Diabetes (EASD). Diabetes Care 35: 1364-1379.

13. Statement of Polish Society of Diabetology (2015) Clinical guidelines for managing diabetes 2015. Diabetologia Kliniczna (Clinical Diabetology) 4: A1A73.

14. American Diabetes Association (2015) Standards of medical care in diabetes-2015: summary of revisions.. Diabetes Care 38: S4.

15. Viera AJ (2012) Resistant hypertension. J Am Board Fam Med 25: 487-495.

16. WHO Collaborating Centre for Drug Statistics Methodology (2015) ATC/DDD Index 2015. WHO Collaborating Centre for Drug Statistics Methodology, Norwegian Institute of Public Health, Oslo, Norway.

17. Ryden L, Grant PJ, Anker SD, Berne C, Cosentino F, et al. (2013) ESC Guidelines on diabetes, pre-diabetes, and cardiovascular diseases developed in collaboration with the EASD: the Task Force on diabetes, pre-diabetes, and cardiovascular diseases of the European Society of Cardiology (ESC) and developed in collaboration with the European Association for the Study of Diabetes (EASD). Eur Heart J 34: 3035-3087.

18. Reiner Z, De Bacquer D, Kotseva K, Prugger C, De Backer G, et al. (2013) Treatment potential for dyslipidaemia management in patients with coronary heart disease across Europe: Findings from the EUROASPIRE III Survey. Atherosclerosis 231: $300-307$

19. Andel M, Grzeszczak W, Michalek J, Medvescek M, Norkus A, et al. (2008) A multinational, multi-centre, observational, cross-sectional survey assessing diabetes secondary care in Central and Eastern Europe (DEPAC Survey). Diabet Med 25: 1195-1203.

20. Grassi G, Cifkova R, Laurent S, Narkiewicz K, Redon J, et al. (2011) Blood pressure control and cardiovascular risk profiles in hypertensive patients from central and eastern European countries: results of the BP-CARE study. Eur Heart J 32: 218-225

21. Kuulasmaa K, Tunstall-Pedoe H, Dobson A, Fortmann S, Sans S, et al. (2000) Estimation of contribution of changes in classic risk factors to trends in coronary-event rates across the WHO MONICA Project populations. Lancet 355: 675-687.

22. Kromhout D (2001) Epidemiology of cardiovascular diseases in Europe. Public Health Nutr 4: 441-457.

23. Mosenzon O, Raz I, Scirica BM, Hirshberg B, Stahre Cl, et al. (2013) Baseline characteristics of the patient population in the Saxagliptin Assessment of Vascular Outcomes Recorded in patients with diabetes mellitus (SAVOR)-TIMI 53 trial. Diabetes Metab Res Rev 29: 417-426.

24. Czech M, Kawalec $P$ (2012) Literature concerning diabetes costs in central and eastern Europe a systematic review and comparison to western Europe, USA and Canada. IJEBL 2: 28-50.

25. ZatoAski W, PrzewoAnniak K, Sulkowska U, West R, WojtyA,a A (2012) Tobacco smoking in countries of the European Union. Ann Agric Environ Med 19: 181-192.

26. McKee M, Bobak M, Rose R, Shkolnikov V, Chenet L, et al. (1998) Patterns of smoking in Russia. Tob Control 7: 22-26.

27. Ezzati M, Obermeyer Z, Tzoulaki I, Mayosi BM, Elliott P, et al. (2015) Contributions of risk factors and medical care to cardiovascular mortality trends. Nat Rev Cardiol 12: 508-530. 